\title{
Lunch and learn: WADA Code 2015 - the key changes
}

\author{
(speakers: Ms. Marjolaine Viret and Ms. Emily Wisnosky; \\ posted by Karen L. Jones, JD, MA)
}

\author{
Karen Jones
}

Published online: 15 May 2014

(C) T.M.C. Asser Instituut 2014

\section{Introduction}

On December 11, 2013, as part of its continuing series of lunchtime presentations focusing on current issues in sports law, the Asser Institute hosted a talk that stepped through the key changes reflected in the recent revision of the World Anti-Doping Code (the "Code" or the "WADC"), due to come into force on January 1, 2015. The speakers, Ms. Marjolaine Viret and Ms. Emily Wisnosky, are part of a research team focused on developing the first comprehensive commentary to the 2015 WADC. ${ }^{1}$ They provided an overview of the key changes reflected in the 2015

K. Jones $(\bowtie)$

The Hague, The Netherlands

e-mail: K.Jones@Asser.nl
WADC that were the result of an extensive revision process of the 2009 WADC led by the World Anti-Doping Agency ("WADA") to enhance and bolster the Code's effectiveness. $^{2}$ The discussed changes were organized

\footnotetext{
${ }^{1}$ Headquartered within the sports law department at the University of Neuchâtel and funded in full by a grant from the Swiss National Science Foundation, their research team is headed by Professor Antonio Rigozzi, a lead practitioner and academic in the fields of sports, doping, and international arbitration. Ms. Viret is an attorneyat-law admitted at the Geneva bar, specializing in sports and health law. She is soon to complete $\mathrm{ahD}$ on evidence issues in anti-doping as an interaction between science and law and will continue the project as a post-doc. Ms. Wisnosky is an attorney-at-law admitted to the California bar and a licensed civil engineer. She currently participates in the 2015 WADC Commentary research project as a doctoral researcher. She also holds an LLM from the University of Geneva in International Dispute Settlement, with a focus on sports arbitration. Prof. Rigozzi is one of the founding partners of Lévy Kaufmann-Kohler a boutique law firm specializing in international arbitration based in Geneva, Switzerland, where he heads the sports arbitration practice. In addition to an active sports law practice, Antonio also teaches and publishes extensively in the fields of both sports and commercial arbitration. He is the author of, inter alia, a well-known treatise on sports arbitration, and a professor of law, including sports law, anti-doping law and international arbitration, at the University of Neuchâtel.

2 A more comprehensive analysis of the key changes can be found in two of the speakers' recent articles: Antonio Rigozzi, Marjolaine Viret, and Emily Wisnosky, 'Does the World Anti-Doping Code Revision Live up to its Promises?', Jusletter 11 November 2013, available at http://www.lk-k.com/data/document/rigozzi-viret-wis nosky-wadc-revision-11-november-2013.pdf (hereinafter referred to as the "Survey Article") and Antonio Rigozzi, Marjolaine Viret \& Emily Wisnosky, 'Latest Changes to the 2015 WADA Code - Fairer, Smarter, Clearer... and not quite Finished [Addendum to the Article: 'Does the World Anti-Doping Code Revision Live up to its Promises? A Preliminary Survey of the Main Changes in the Final Draft of the 2015 WADA. For a briefer look at the key changes, see also Antonio Rigozzi, Marjolaine Viret, and Emily Wisnosky, 'A New Code for a New Era in the Fight Against Doping in Sports,' Global Sports Law and Taxation Reports (March 2014).
} 
under three revision goals ${ }^{3}$ : (I) smarter doping detection and prosecution; (II) tackling the real problems; and (III) procedural enhancements.

\subsection{Smarter doping detection and prosecution}

The first revision goal reflects a stronger orientation towards intelligence gathering and investigations, shifting away from a primary reliance on punctual testing in antidoping control. The speakers reviewed the amendments geared towards optimizing the resources of Anti-Doping Organizations ("ADO"s) by introducing a new focus on strategy and intelligence to uncover anti-doping rule violations. This shift in focus arose at least in part from the recognition that several recent high-profile cases (such as the Lance Armstrong case) were largely intelligence based and thereby exposed the weaknesses in a brute force testing strategy. Aside from the more symbolic signals to reflect this new focus (such as modifying the titles of both the IS for Testing and Article 5 of the WADC to include "Investigations" in addition to "Testing"), the speakers highlighted the amendments made in Article 5.8 of the WADC and the addition of Article 11 of the International Standard for Testing and Investigations ("ISTI") designed to expand the capacity of ADOs to gather intelligence. The new ADO obligations comprise mainly the ability to process (including collecting, storing, analyzing, and sharing) of intelligence.

The speakers also highlighted amendments made to introduce a strategic "risk-based" approach to Testing and analysis to enhance the effectiveness of Doping Control. These amendments are to be enshrined in a Technical Document that will provide a "sport-specific" assessment of the risk of abuse of certain substance, which ADOs shall use as a starting point to develop a Test Distribution Plan that is "effective, intelligent and proportionate" (Article 5.4.2). The same Technical Document will include a component with differentiated "analysis menus," that use risk assessment for determining for which substances an Athlete's samples should be tested in a particular sport (Article 6.4).

Other important amendments mentioned are geared towards adjusting the analysis requirements to better fit the realities of the anti-doping effort and available resources. The first is an increase in the decision limit for

\footnotetext{
${ }^{3}$ Along with the publication of version 4.0 of the 2015 WADA Code, WADA published an overview document "Significant Changes Between the 2009 Code And the 2015 Code, Version 4.0" in which it grouped the key amendments under seven revision themes (hereinafter referred to as the Overview), available at http://www.wada-ama.org/ Documents/World_Anti-Doping_Program/WADP-The-Code/Code_ Review/Code\%20Review\%202015/Code\%20Final\%20Draft/WADC2015-draft-version-4.0-significant-changes-to-2009-EN.pdf. The revision goals were loosely based on these themes.
}

cannabinoids, a very commonly appearing substance in an Athlete's sample that serves as a controversial topic in the anti-doping movement mainly due to the amount of resources spent pursuing associated violations in light of the drug's tenuous (at best) links to performance enhancement. The concentration at which a positive test for cannabinoids is reported as an anti-doping violation was substantially increased, with the goal to cut back the number of violations involving this substance when used as a social drug out-of-competition. ${ }^{4}$ The speakers also presented the introduction of an explicit "cut-off" point (when the results of sample analysis have been communicated to the Athlete), after which the sample may not be subject to further analysis (Article 6.5). Finally, the speakers addressed a new presumption added to reduce the risk of challenges directed against analytical tools, which provides in essence that WADA approved analytical methods and decision limits are presumed to be scientifically valid (Article 3.2.1).

\subsection{Tackling the real problems}

The second focus of the presentation was on the substantive amendments made to the sanctioning regime and on the amendments designed to increase the scope of ADO's authority to punish the Athlete's entourage, which can play a key role in helping Athletes to dope.

\subsubsection{Substantive amendments made to the sanctioning regime}

As a general notion, the main change made to the sanctioning regime is the increase in the length of the initial period of ineligibility from two years to fours for all socalled "intentional" anti-doping rule violations. This amendment was made in line with the first prong of WADA's stated policy objective of providing harsher penalties for the "real cheats." According to the speakers, the efficacy of this approach hinges on setting forth a universal and harmonized understanding of the term "intentional" that transcends the myriad nuanced definitions of this term across the world's many systems of law.

The speakers broke the definition of "intentional" provided in Article 10.2.3 down into three component parts, or "branches." The first branch, which comprises the reference to "cheating" in the first sentence of Article 10.2.35 was referred to as the "contextual" branch and was described as playing the

\footnotetext{
${ }^{4}$ WADA Laboratory Committee, Decision limits for the confirmatory quantification threshold substances of 11 May 2013, Technical Document TD2013DL.

5 "As used in Articles 10.2 and 10.3, the term "intentional" is meant to identify those Athletes who cheat".
} 
role of setting the tone of the definition. The second branch comprises the "Legal Core" identified as comprising the technical elements necessary to determine that a violation was committed intentionally. ${ }^{6}$ This Legal Core was interpreted by the speakers to provide in substance that the violation needs to be committed either with knowledge, or reckless (dolus eventualis). The third and final branch was presented as the "Exceptions" to the general definition that provides a special assessment of "intentional" where the violation involves substances prohibited only In-Competition. ${ }^{7}$

The speakers then turned to the second prong of WADA's stated policy objective: to provide more flexibility in cases of inadvertent doping. The speakers pointed to several amendments made under this heading, the most significant of which are as follows: the addition of a new provision to deal with Contaminated Products, a reworking of the approach to deal with Specified Substances, and a slight modification of the definition of "No Significant Fault or Negligence." The speakers compared the treatment of Contaminated Products under the 2015 and 2009 versions of the WADC, noting in particular that the new provision provides a broader window of available sanction lengths than the 2009 version. In the new provision, if an Athlete can establish No Significant Fault or Negligence, then violations involving non-Specified Substances have an available sanction length of zero-to-two years, depending on the Athlete's degree of fault. Under the 2009 WADC, the shortest length of the violation that an Athlete could hope for is 1 year.

The speakers also compared the treatment of Specified Substances under the 2009 and 2015 versions of the Code, as the approach changed quite significantly in the 2015 version. Previously, if Athletes could establish a lack of performanceenhancing intent, and the origin of substance, then the associated length of their initial period of Ineligibility would be from zero-to-two years, depending on the Athlete's degree of Fault. In other words, the Athlete could have a significant degree of Fault, but so long as they were able to establish a lack of performance-enhancing intent, then they could still hope to receive some reduction. However, under the 2015

\footnotetext{
${ }^{6}$ Article 10.2.3, second sentence: "The term, therefore, requires that the Athlete the Athlete or other Person engaged in conduct which he or she knew constituted an anti-doping rule violation or knew that there was a significant risk that the conduct might constitute or result in an anti-doping rule violation and manifestly disregarded that risk."

7 Article 10.2.3, third and fourth sentences: "An anti-doping rule violation resulting from an Adverse Analytical Finding for a substance which is only prohibited In-Competition shall be rebuttably presumed to be not "intentional" if the substance is a Specified Substance and the Athlete can establish that the Prohibited Substance was Used Out-of-Competition. An anti-doping rule violation resulting from an Adverse Analytical Finding for a substance which is only prohibited In-Competition shall not be considered "intentional" if the substance is not a Specified Substance and the Athlete can establish that the Prohibited Substance was Used Out-of-Competition in a context unrelated to sport performance."
}

WADC sanctioning regime, the speakers highlighted the fact that Athletes may seemingly only receive a reduction down from a 2-year sanction if they are able to establish what has traditionally been a rather exacting standard of No Significant Fault or Negligence.

As a final point regarding the revised sanctioning regime, the speakers also touched on the compatibility of the 2015 WADC with international concepts of human rights and proportionality. They noted that, as for prior versions of the WADC, WADA sought a legal opinion to ensure that the key changes are aligned with well-accepted principles of human rights and proportionality. The legal opinion assessed the changes favorably (with some recommended revisions). The Code itself also incorporates language stating its alignment with these principles and the need for proportionality in its application. ${ }^{8}$

\subsubsection{Increased scope of authority vis-à-vis an athlete's entourage}

The last group of amendments with respect to substantive issues the speakers touched upon includes those amendments designed to broaden the reach of the Code in targeting the athlete's entourage. The speakers divided these amendments into two distinct categories: those designed to reach the entourage through direct means, and those that rely upon more indirect means. The direct means are focused on expanding the jurisdiction of ADOs over Athlete Support Personnel, as well as a potentially rather intrusive newly formed requirement for disciplinary rules that would ban the "unjustified" use of prohibited substances among these support personnel. The indirect means focus on the Athlete and consist of the introduction of a new violation that prohibits Athletes from associating with Athlete Support Personnel who have a history of doping-related activities, under certain specific circumstances (Article 2.10).

\subsection{Procedural enhancements}

The category of "procedural enhancements" discussed includes a range of new amendments geared mainly towards protecting the due process rights of Athletes in anti-doping proceedings, while also encouraging greater efficiency and efficacy in pursuing anti-doping violations among ADOs.

\footnotetext{
8 The speakers mentioned in particular the following three instances where human rights and proportionality are mentioned in the 2015 WADC: (1) Introduction: "The Code has been drafted giving consideration to the principles of proportionality and human rights;" (2) Introduction: "...[these sport-specific rules and procedures] are intended to be applied in a manner which respects the principles of proportionality and human rights;" (3) Article 10.10 requires that financial consequences must be proportional.
} 


\subsubsection{Improved collaboration among ADOs}

The speakers touched upon a group of amendments geared towards strengthening the powers of ADOs, especially by encouraging an increased level of collaboration among NADOs and IFs. ${ }^{9}$ The speakers noted that the emphasis appeared to be on reducing the imbalance between the value attributed to the NADOs and the superior value recognized to IFs in different domains. The two main areas where the improvements related to collaboration among ADOs are in event testing and the process of issuing and recognizing TUEs.

\subsubsection{Fair hearings in the disciplinary proceedings}

The speakers also addressed the amendments aimed at strengthening the hearing process in anti-doping procedures (Article 8.1). Instead of defining the elements of a fair hearing in a list format, which was the approach taken in the 2009 WADC, the 2015 WADC contains a broader statement, setting forth that ADOs are required to offer those accused of committing an anti-doping rule violation, a fair hearing at some point in the results management process. The speakers suggested that while the new formulation has the advantage of conciseness, it is not clear that the world's ADOs will hold a shared understanding of what is exactly encapsulated in the notion of a "fair hearing." This concern is heightened by the fact that the only reference for understanding the concept of a fair hearing is an allusion to the European Convention on Human Rights and accepted principles of international law made in the comment to Article 8.1, which does not provide a clear guidance as to what level of authority these mentioned sources of law should hold. Accordingly, the speakers wondered if the new formulation might lead to less legal certainty, less concreteness, and less worldwide harmonization in this important area.

\subsubsection{The court of arbitration for sport and the WADC}

The speakers mentioned four amendments that have a direct impact on anti-doping proceedings at the Court of Arbitration for Sport (the "CAS").

The first of these amendments is found in Article 3.2.1 and concerns the new presumption that "[a]nalytical methods or decision limits approved by WADA after consultation within the relevant scientific community and which have been the subject of peer review" are scientifically valid. Any challenge directed at rebutting this presumption must be communicated to WADA, which has the discretion to intervene in the CAS proceedings and request that the CAS panel appoint an

\footnotetext{
9 These amendments include those made to the definition of "Athlete" in Appendix 1 of the Code, and Articles 5.2.6, 5.3, and 7.1.
}

"appropriate" scientific expert. According to the speakers, this amendment raises numerous questions, for example in terms of which party/institution will cover the cost of such an expert, and what qualifications would be necessary to qualify as an "appropriate" expert.

The second is an amendment that gives the parties the option, upon unanimous agreement, to skip an initial hearing process in favor of bringing a hearing involving an anti-doping rule violation directly before the CAS. The underlying reasoning, which is set forth in the Comment to Article 8.5, was explained as avoiding the unnecessary cost of an initial hearing when the parties are satisfied that their needs are met by bringing the case directly to the CAS. The speakers raised questions about the cost of this "initial" hearing: as Article R65.2 of the Statutes of the Bodies Working for the Settlement of Sports-Related Disputes (the "CAS Code") ${ }^{10}$ defines only international disciplinary decisions as free of charge, these initial hearings would be subject to the rather steep costs of a so-called "ordinary" arbitration procedure, unless a special mechanism was defined to place them under the auspices of the free-ofcharge rule.

The third amendment mentioned under this heading allows parties to bring "cross appeals or other subsequent appeals" (Article 13.2.4 of the WADC), in contradiction to the CAS Code, which no longer provides for this possibility in appeal arbitration proceedings. According to the speakers, the most interesting aspect of this amendment is the questions it raises with respect to the hierarchy between the rules adopted by the ADOs in accordance with the WADC and the CAS Code itself. Would CAS panels be legally required to follow this new amendment, or, in the negative, would they choose to do so on their own volition?

The last of the amendments that mention the CAS Code (Articles 13.1.1 and 13.1.2 of the WADC) do not seem to directly contradict the CAS Code, but nevertheless provides procedural direction to the CAS Panels. Article 13.1.1 provides that the scope of review is "not limited to the issues or scope of review before the initial decision maker." Article 13.1.2 provides that the CAS does not need to "give deference" to the discretion of the body that originated the decision under appeal. The speakers noted that neither of these amendments seems out of sync with the CAS current practice and rather confirm the central notion that CAS panels will conduct a full review of the facts and law of each case.

\footnotetext{
${ }^{10}$ The 2013 version of the CAS Code is available at: http://www.tascas.org/d2wfiles/document/4962/5048/0/Code20201320corrections20 finales $20 \% 28 \mathrm{en} \% 29$.pdf.
} 


\section{Conclusion}

In conclusion, the speakers revisited the key themes under which these new amendments were made, namely, the focus on smarter instruments to detect doping, providing harsher penalties for real cheats, providing more flexibility for inadvertent dopers, creating mechanisms to "reach" the
Athlete's entourage, and finally enhancing due process in anti-doping disputes.

As a final note, the speakers emphasized the key role that the CAS will play in coming to a harmonized and proportional interpretation of all these new provisions. 